\title{
Road traffic growth and capacity in a holiday district (Dorset)
}

\author{
by \\ J. I. Whitehead, Ph.D., M.Sc.(Eng.), M.I.C.E.
}

Mr W. P. Winston (Messrs Freeman, Fox and Partners) wrote that the Paper constituted a valuable step forward in the development of traffic forecasting. However, if a forecasting method was to supersede the use of simple growth factors one must have confidence that it was more reliable over the life of the projects it was used to design than the method it replaced. Using this test the Author's method might suffice in Dorset but one would be reluctant to use it more widely.

63. The proposed constant $k$ was anomalous as it was used as a constant for each section of road and not for population pairs. For example, in Table 3 the pair Dorchester with Poole/Bournemouth was common to stations 15 and 29 which were a few miles apart and had values of $k$ of 3.608 and 2.929 respectively. Such variations, which must apply to many populations pairs, represented discontinuities in the traffic volume between population pairs. The most probable explanation was that $k$ was not a constant but a function relating to both traffic generation and distribution.

64. In $\$ 10$ an analysis of journey length was given. Did this analysis refer to journeys while at work? Recent data for the distribution of journeys by purpose were tabled below:

TABLE 6: JOURNEYS BY PURPOSE

\begin{tabular}{|c|c|c|c|}
\hline & $\begin{array}{c}\text { To or } \\
\text { from work }\end{array}$ & $\begin{array}{l}\text { Business, } \\
\text { i.e. at work }\end{array}$ & $\begin{array}{l}\text { Personal } \\
\text { business and } \\
\text { other }\end{array}$ \\
\hline $\begin{array}{l}\text { M1 study }{ }^{30} \\
\text { A45 between Birmingham and Coventry }{ }^{31} \\
\text { London traffic survey, external cordon }\end{array}$ & $\begin{array}{l}4.5 \% \\
18.5 \% \\
38.6 \%\end{array}$ & $\begin{array}{l}54 \cdot 5 \% \\
61 \cdot 0 \% \\
23 \cdot 1 \%\end{array}$ & $\begin{array}{l}41 \cdot 0 \% \\
20 \cdot 5 \% \\
38 \cdot 3 \%\end{array}$ \\
\hline
\end{tabular}

65. The Author's conclusions might therefore apply with certainty to about half the journeys. Little was known about 'personal business and other' journeys in rural areas. Did the Author think that a study of journeys by purpose would help to resolve variations in $k$ ?

66. In $\$ 19$ the Author suggested that when populations doubled, traffic volumes would increase two-fold rather than four-fold. One would expect work journeys to be related to population and employment, but that, on theoretical grounds, journeys for other purposes would more than double, since urban expansion in progressive communities was not simply a population expansion but implied economic development. In larger communities there was more specialization (division of labour) and hence one would expect more journeys. To test this possibility it was necessary ot exclude work journeys and it was desirable to exclude side effects such as were caused by differences in distance. The only origin/destination data ${ }^{33}$ traced which satisfied these conditions was for travel between London and Glasgow, and London and Edinburgh. The population ratio Edinburgh: Glasgow was $1: 2 \cdot 25$, and the

* Proc. Instn civ. Engrs, vol. 30, March 1965, pp. 589-608. 
distances from London by road were $\mathbf{3 7 3}$ and 394 miles respectively. Journey ratios were estimated as given in Table 7 below.

TABLe 7

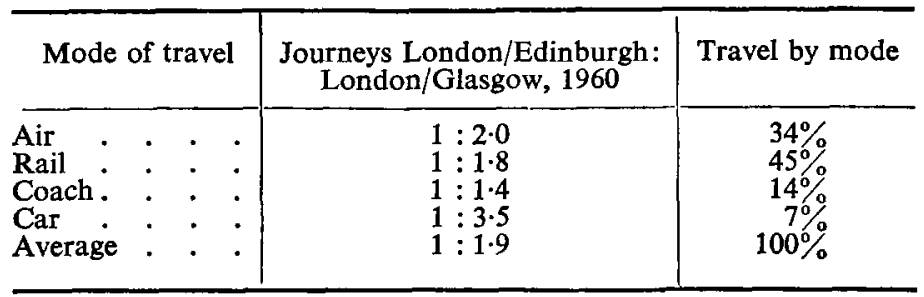

These figures must be treated with reserve. At the time, air travel was expanding rapidly and the car travel figures related to relatively few journeys and were derived from a small sample. The figures did suggest, however, that when a population doubled traffic volume increased rather more than two-fold for journeys other than those to and from work.

67. In $\$ 34$ the Author concluded that London would have little influence on traffic volume in Dorset. This conclusion was presumably based on present-day journey speeds of about $35 \mathrm{mile} / \mathrm{h}$. Construction of a motorway system might be expected to give journey speeds of up to $55 \mathrm{mile} / \mathrm{h}$ compared with $50 \mathrm{mile} / \mathrm{h}$ and 70 mile/h proposed for railway trunk routes. ${ }^{34}$ On the outskirts of London, ${ }^{35}$ $42.2 \%$ of journeys were by car and $40.4 \%$ by rail, but the majority of the railway journeys were made by commuters. Consequently car usage was high compared with the $7 \%$ quoted for journeys between London and Scotland. Between London and the West Country the percentage of car usage might be expected to be between these extremes and one would expect the percentage to be increased by the construction of motorways. In the circumstances, the conurbations might have rather more effect on traffic in Dorset than the calculation in $\$ 34$ implied. In the general case it was relevant to remember that in conurbations travel time to a principal railway station might be an appreciable part of the journey time as a whole.

68. Finally, in $\$ 3$ the Author drew attention to the lack of sociological data on which to base traffic forecasts. Such difficulties unfortunately might be the lot of research workers, but for large-scale studies it was feasible to collect further data. This had been done for urban studies and at least one county ${ }^{36}$ had executed a home interview study of its urban and some of its rural areas for the purpose of development plans. This was a sample study and the sample was selected to give a standard error of $\pm 5 \%$ in urban areas rising to $\pm 10 \%$ in rural areas at a confidence interval of $95.0 \%$. It would be of interest to have the Author's comments on what additional data might be obtained, given the opportunity.

Mr J. Fone (Assistant County Surveyor, Norfolk) wrote that he would like to ask whether the Author could give any information as to how Table 4, which was described as empirical, was built up. He had never understood that 6000 p.c.u./d was the capacity of a two-lane carriageway, but rather that if this was the daily flow in August a two-lane carriageway would not cause undue congestion. Even with this figure there were probably cases in the rural areas on the outskirts of a town with heavy commuter traffic when even this figure would only cause congestion for a short period at morning and night when commuters mixed with peak holiday traffic. This justified the Author's suggestion that with 6000 p.c.u. a day flow there might be congestion for half an hour per day. If the summer flow increased to 9000 the congestion would probably extend to one hour per day, but this would be limited to three months, which would not make overall conditions worse if the winter flow was reduced. 
70. Considering again the two-lane carriageway, the Author had increased the flow by 1000 for every integer of the variation fraction. Assuming the seasonal variation summer flow to last for three months and the winter for nine months, and using the figures from line 1 of Table 4:

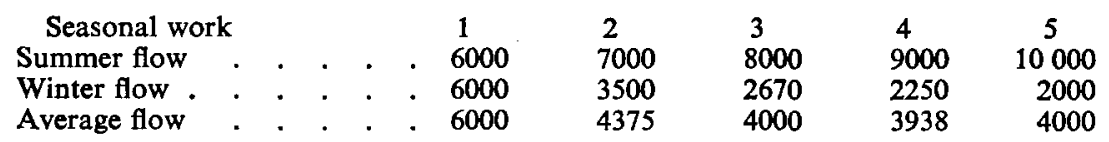

From this it could easily be seen that if the seasonal variation exceeded four, then the average flow would increase, so one must not extend the Author's table if, as in Norfolk, the seasonal variation exceeds five.

71. It was well known that on medium and heavy traffic routes an increase in traffic did not cause a directly proportionate increase in congestion, but a much larger one. Considering the example given above in this light, the figures on the right hand of the table should be reduced.

72. If one was considering a road which was taking 10000 vehicles per day in the summer it did not really matter whether the winter figures fell below 2000, and in Norfolk there were a number of roads where the variation was of the order of 10 . It must therefore be considered whether the 10000 p.c.u. was a regular summer flow or whether it was biased due to heavy weekend or heavy peak-hour flow. In Norfolk the difference in traffic flow to seaside resorts which catered mainly for weekly holidays and those which catered for day trippers was very noticeable. The former produced heavy flows throughout the day at weekends and the second produced peak-hour flows.

73. It was obvious that in a country with seasonal variations in traffic a table such as that the Author gave was necessary in order to assess priorities, but it would probably have to be extended so that instead of giving seasonal variation against summer flow it would give maximum hourly flows against number of hours per year when this occurred, rather on the old Ministry of Transport basis of designing on the hourly flow occurring 30 times per year. A new table could be devised using the peak hour flow of $1 / 10 \times 6000=600$ p.c.u. occurring morning and night throughout the year, say 6000 times, and the Author's figure of 2000 p.c.u. (\$50) occurring say four hours per week for ten holiday weeks.

The Author, in reply, agreed with Mr Winston's comment that proof was needed that the forecasting method suggested in the Paper was valid for places other than Dorset. Each required its own study to see if the findings for Dorset were applicable.

75. As to the value of $k(\$ 31)$ he had concluded that $k$, in his definition, was not a constant, probably because of over-simplification of the method. Due to the variation in its values, it was decided to eliminate it when forecasting. For his purposes, the Author doubted the need to find a more exact value for $k$ by elaborating the method by considering types of journey purpose separately. The ultimate objective was to forecast carriageway widths in numbers of lanes, and the large increase in capacity made available by the addition of one lane made refinement of the meaning of $k$ rather pointless.

76. $\$ 10$ summarized an analysis of daily mileages, and not of individual journeys. If the daily mileages were assumed to be journey lengths, they represented maxima for journey lengths, and included all purposes of journey. He had no information on the distribution of journey purposes in Dorset. The remarkable similarity between the distributions of daily mileages for Mr Leeming and himself seemed to indicate that other personal records might give similar results. Other records of daily mileages would be welcomed to check this, but the records must extend over several years. 
77. Regarding $\$ 19$, it should be remembered that in that particular paragraph the Author was dealing with traffic volume increases due solely to population increases, assuming that all other influences remained constant. The idea that if a population doubled, traffic volumes would do no more than double was based, within this limitation of growth influences, on the constancy of vehicle mileages per annum over many years. For cars this was rather less than 10000 miles per annum. It did not appear logical to the Author to suggest that an increase in population would cause an increase in annual vehicle mileages. However, when influences other than population were included, notably the increase in numbers of vehicles per person, doubling a population would clearly cause far more than a doubling of traffic, and the Author implied this in his forecasts.

78. The conclusion in $\S 34$ that London had little influence on Dorset traffic, was valid only within the seventeen years for which the Author made his forecasts. $\mathrm{He}$ agreed that a drastic reduction in journey time caused, for example, by the construction of a motorway from London to Dorset would greatly increase the influence of London on Dorset traffic. However, there seemed to be very little possibility of such a motorway being constructed for very many years, and its effect should not be included in forecasts until there was some indication that it was likely to be considered as a possible new route.

79. The Author would regard the collection of sociological data, as had been done in Kent, to be primarily the task of Town Planners, but no such survey had been made in Dorset. The types of data which might cause traffic changes were the general prosperity and purpose of a town, and the possibility of changes in social and monetary status which might promote the demand for cars. One would like to know such things as the shopping turnover in a town, the capacity of office and administrative services to attract traffic, and the income and age groups of the inhabitants. These types of information could only be obtained from home interviews, and the Author had no facilities for carrying out these in Dorset.

80. With regard to Mr Fone's comments, in describing Table 4 as empirical the Author meant that it was based on his opinions, and not on calculations, and he would therefore hesitate to be dogmatic about the accuracy of the capacity ranges he had suggested. One tended to take the Ministry of Transport's capacity criteria perhaps too literally. The Author believed they were low in relation to what we could afford to construct, and 6000 p.c.u. per day would certainly not cause undue congestion on a two-lane carriageway even if the peak hour was as high as $1 / 5$ th of the 16-hour average, compared with the Ministry of Transport's suggested 1/10th.

81. Seasonal variation occasionally exceeded 5 in Dorset, and might be as high as 7 or 8 , but the large seasonal variations tended to occur on the roads which had very small flows in the winter. B3351 near Swanage was an example. Here seven times the winter flow was still less than 6000 p.c.u. per day. Where the winter flow was higher, the seasonal variation tended to be less, and on a class I road, seldom exceeded 3. The Author was surprised that a seasonal variation as high as 10 occurred in Norfolk.

82. The Author agreed that the peak flows for weekly holidaymakers and for day trippers were quite different. The peaks for day trippers were very sensitive to sudden changes in the weather, whereas weekly holiday travel was not, and the latter always occurred at week-ends.

83. The Author had attempted, in a previous Paper $^{2}$ to compare Dorset peak flows with the American 30th hour criterion, and Mr Fone might find this of interest. Where seasonal variation was large, use of the 30 th hour criterion cauld lead to extravagant design.

84. The Author's papers on holiday traffic were based generally on dissatisfaction with the standards suggested by the Ministry of Transport, and he was convinced that more guidance and greater flexibility in applying the standards were needed, or, better still, new standards for holiday traffic should be devised. 


\section{REFERENCES}

30. CoBURn T. M. The London-Birmingham motorway: traffic and economics. Road Research Technical Paper No. 46, London, H.M.S.O., 1960. Part 1 Traffic Investigation. Table 8, p. 28.

31. DunCan N. C. Purpose of journeys by private car on the Coventry-Birmingham Road, A45. Road Research Laboratory, Laboratory Note No. LN/70/NCD, March 1962. Table 1, p. 3.

32. London Traffic Survey Report. London, London County Council, 1964. Vol. 1. Table 6-39, p. 120 .

33. 21st Hearing of the Air Transport Licensing Board, 1961. Quoted in Flight, 1962, 82 (2 Aug.), pp. 159-160.

34. British Railway Board Report. The development of the major railway trunk routes. London, British Railways Board, Feb. 1965. Table 8, p. 34.

35. London Traffic Survey Report. London, London County Council, 1964. Vol. 1, Table 6-37, p. 119.

36. Kent County Council Planning Department. Kent development plan Quinquennial Review 1963, Report on the Survey and Analysis Part Four: Sample Survey of Households. Maidstone, Kent County Council Supplies Department, Sept. 1964. Vol. 1, pp. 134-137. 